\title{
Mucous Extravasation Cyst: A Case Report
}

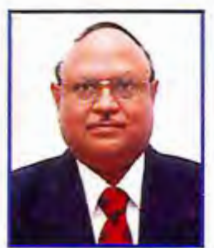

Dr. V. V Subba Reddy

Professor \& H.O.D.

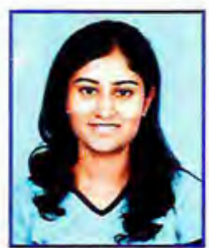

Dr. Preeti

PG Student

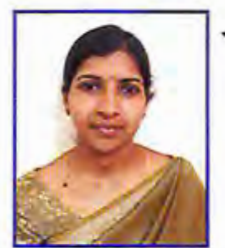

Dr. Poornima

Asso. Professor

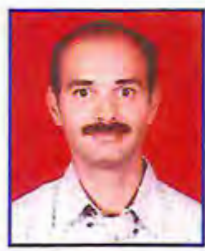

Dr. Manjunath

Professor

Dept. of Pedodontics, CODS

Dept. of Oral Surgery, CODS

\section{Introduction}

The mucocele is a common lesion of the oral mucosa that results from rupture of a salivary gland duct and spillage of mucin into the surrounding soft tissues. The spillage is often the result of local trauma, although there is no known history of trauma in many cases. ${ }^{1}$ These are most often seen in children and young adults, they may occur at any age, with almost two-third of all mucoceles occurring during the first three decades of life. Both males and females are equally affected. The mucosal surface of the lower lip is the favoured site, followed by the buccal mucosa, the floor of the mouth, ventral tongue and palate. ${ }^{2}$

Patients usually complain of a painless swelling which is frequently recurrent. They may be present for only a few days but some patients tolerate them for months or even years before seeking treatment. The swelling may develop suddenly at mean times and many drain spontaneously at intervals. Some ten percent of patients are able to relate the development of cyst to trauma. ${ }^{3}$ Small mucoceles may require no surgical treatment provided the patients find them no hindrance. However, to minimize the recurrence surgical excision is the treatment of choice.

\section{Case report}

A 10 year old girl presented to the department of Pedodontics and preventive dentistry, College of dental sciences, Davangere, with the chief complaint of pain in lower right cheek region. Clinical history revealed that the lesion had appeared a month ago and subsided spontaneously. Over the period of time, the lesion recurred as a painful swelling which increased to the present size over a period of one month. Intra-oral examination revealed the presence of oval swelling, $1.5 \mathrm{cms} \times 2.0 \mathrm{cms}$ in diameter, on the lower right cheek mucosa opposite to the first and second premolars [Figure: 1]. There was no other associated findings and patient had maintained good oral hygiene.

Surgical excision was chosen as the treatment of choice. Surgical intervention was performed under local anesthesia after obtaining the informed consent from the parent. The boundaries of the mucocele were delineated and then a circular incision was made around the lesion (Figure 2). Dissection was continued in the plane adjacent to the capsule, down to the muscle layer of the cheek and the cyst was removed. All remaining adjacent minor salivary glands in the field, were excised to reduce the chance of recurrence (Figure 3). The area was thoroughly inspected and bleeding was arrested.

The wound edges were undermined gently, and the wound closed with a black silk suture (Figure 4, 5). Care was taken to avoid any tension on the sutures. The removed surgical specimen was histopathologically examined confirming the diagnosis of mucocele (Figure $6,7,8$ ). The patient was recalled after seven days for suture removal. The patient was then followed up after one month to evaluate the healing.

\section{Discussion}

Mucous extravasation cyst, also known as "mucocele" is a swelling composed of pooled mucus that has escaped into the connective tissue from a severe excretory duct. As the cyst lack an epithelial lining they are not true cysts. ${ }^{2}$ Mucoceles capable of causing airway obstruction are known as plunging mucoceles, whereas actual mucoceles represent inflammatory polyps. Although mucoceles can become large, most are of limited size. As they enlarge, the gland that supplies mucin through the severed duct i.e. feeder gland becomes compressed, eventually developing obstructive changes. ${ }^{2}$

Mucoceles may lie fairly deep in the tissues or be exceptionally superficial. Superficial lesions present with a bluish, translucent cast, the blue color imparted by the spilled mucin below the mucosal surface. The deeper lesions are of normal color because of the thickness of the overlying tissue. ${ }^{4}$

A differential diagnosis is important because mucoceles of minor salivary origin are bluish and the history of trauma may be vague, other lesions that appear blue must be considered. Of these, low grade muco-epidermoid carcinomas are most significant. They will also produce mucin in vacuolated spaces within the tumor, imparting the blue color. Cavernous hemangiomas, and a venous varix will give rise a similar appearance. Although rare, a vascular leiomyoma appears blue and has a predilection for the lip. ${ }^{5}$ 
Mucoceles can be treated under local anesthesia by surgical excision with or without hydrodissection. ${ }^{6}$ The underlying feeder glands should be removed in continuity with the Mucocele or extirpated from the base of the surgical bed after the removal of the lesion. It is an attempt to minimize the chance of recurrence. This technique was selected since it is a conservative method.

However, lasers have been used more often over the recent past. Mucocele excision using the laser is especially advantageous in children, because sutures are not necessary and there is less post-operative pain and swelling when compared with excision using a scalpel or electrocautery?

\section{References}

1. Brad W. Neville, Dongles D. Damm, Cari M. Allen, Jenny Bouquet: Oral and Maxillofacial Pathology. 2nd Ed. W.B. Saunders Co., pp 389.

2. Philip Sapp, Lewis Eversole: Contemporary Oral and Maxillofacial Pathology. 2nd Ed Mosby Pub., pp 332-34.

3. Mervyn Shear: Cysts of the Oral Regions. 3rd ed. Varghese Publishing House, pp 212-21.

4. Shafer, Hine, Levy: Shafer's Textbook of Oral Pathology. 5th ed. Elsevier Pub. pp 747-749.

5. Robert Marx, Diane Stern: Oral and Maxillofacial Pathology; a Rationale for Diagnosis and Treatment. Quintessence Pub. Co., Inc.

6. $\quad$ Eugene N. Myers, Robert Ferris: Salivary Gland Disorders. Springer Pub. pp 180-81.

7. Leonard Kaban, Maria Troulis: Pediatric Oral and Maxillofacial Surgery. Saunders Pub. pp 153.

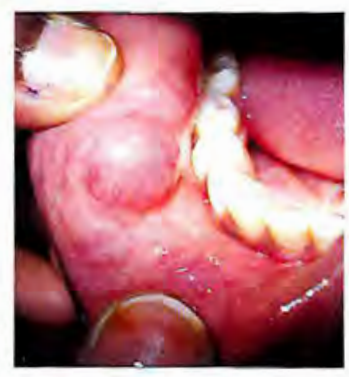

Fig. 1

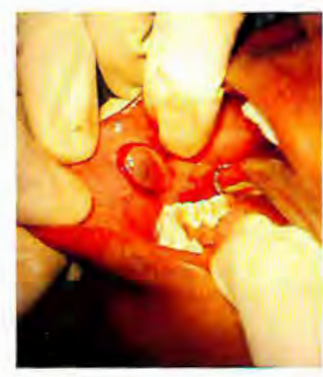

Fig. 2

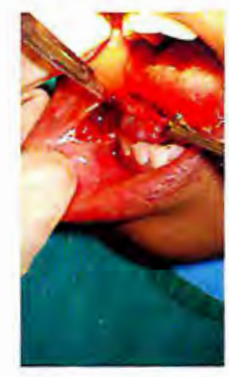

Fig. 3

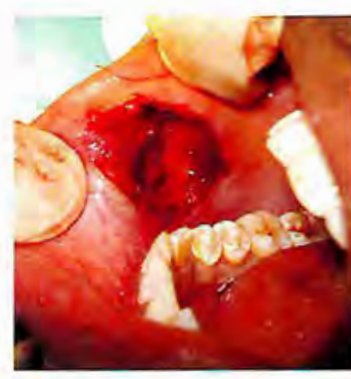

Fig. 4

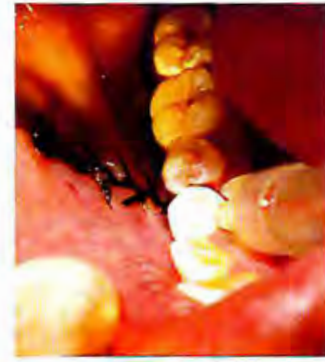

Fig. 5

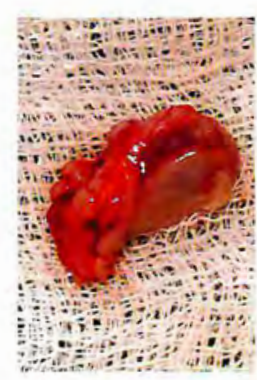

Fig. 6

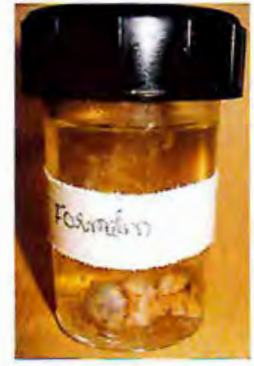

Fig. 7

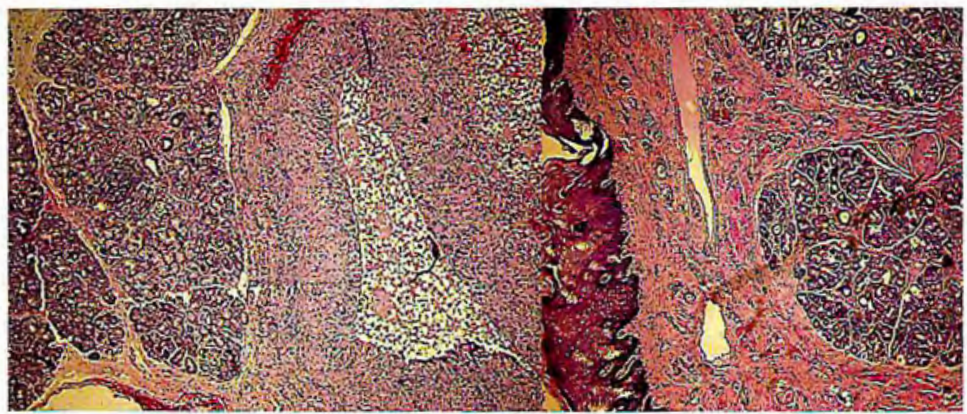

Fig. 8 